\title{
Selective mixed potential ammonia exhaust gas sensor for harsh environments
}

Daniela Schönauer, Ralf Moos

Universität Bayreuth

Lehrstuhl für Funktionsmaterialien

95440 Bayreuth, Germany
Kerstin Wiesner, Maximilian Fleischer

Siemens AG

CT PS 6

81739 München, Germany

\begin{abstract}
An ammonia exhaust gas sensor for harsh environments enables to control the $\mathrm{NH}_{3}$ emission downstream an SCR (selective catalytic reduction) catalyst, which is used to reduce the $\mathrm{NO}_{\mathrm{x}}$ emissions of diesel engines and industrial plants. A novel mixed potential $\mathrm{NH}_{3}$ exhaust gas sensor for selective $\mathrm{NH}_{3}$ detection showed in synthetic exhaust a very good correlation between sensor voltage and $\mathrm{NH}_{3}$ concentration with a marginal $\mathrm{NO}_{\mathrm{x}}$ cross interference. First tests in real exhaust gas to proof the applicability showed promising results.
\end{abstract}

\section{Introduction}

Minimizing the emissions of vehicles and plants is a huge concern of the society. More stringent $\mathrm{NO}_{\mathrm{x}}$ emission standards result in the application of exhaust gas aftertreatment systems like the SCR-system. $\mathrm{NO}_{\mathrm{x}}$ is reduced by addition of $\mathrm{NH}_{3}$ or $\mathrm{NH}_{3}$-forming substances to the exhaust pipe and a following selective reduction reaction at the catalyst to $\mathrm{H}_{2} \mathrm{O}$ and $\mathrm{N}_{2}$. An ammonia sensor would enable to measure the $\mathrm{NH}_{3}$ slip and therefore would provide a closed-loop control system and an active OBD (on board diagnosis). Consequently, an increasing $\mathrm{NO}_{x}$ conversion rate could be achieved [1, 2]. In this work, the sensor characteristic of a novel $\mathrm{NH}_{3}$ sensor is described including the influence of important cross sensitivities like nitrogen oxides and the air-to-fuel ratio $\lambda$. Additionally, initial engine test bench results are discussed.

\section{Experimental}

The schematic sensor setup in ceramic multi-layer technology is described in Fig. 1. The sensor consists of two alumina substrates. One substrate is the heater substrate including a platinum heater structure and a dielectric protection cover, both realized in thick film technology. The second substrate is the sensor substrate: First, a solid electrolyte layer (yttria stabilized zirconia, YSZ) is screen-printed. On top, two porous gold electrodes are applied, whereas one electrode is covered afterwards by an additional porous catalytic active film. As a catalyst material, commercially available materials with proven long-term stability in the exhaust and known catalytic behaviour are examined. In this contribution, the properties of $\mathrm{V}_{2} \mathrm{O}_{5}-\mathrm{WO}_{3}-\mathrm{TiO}_{2}$ as coating material are characterized. Tests are conducted at a sensor temperature of $550{ }^{\circ} \mathrm{C}$ in a gas composition near $\lambda=2\left(10 \% \mathrm{O}_{2}, 6.5 \% \mathrm{CO}_{2}, 7 \% \mathrm{H}_{2} \mathrm{O}, \mathrm{N}_{2}\right.$ balance $)$ with different $\mathrm{NH}_{3}$ and $\mathrm{NO}_{\mathrm{x}}$ concentrations. 


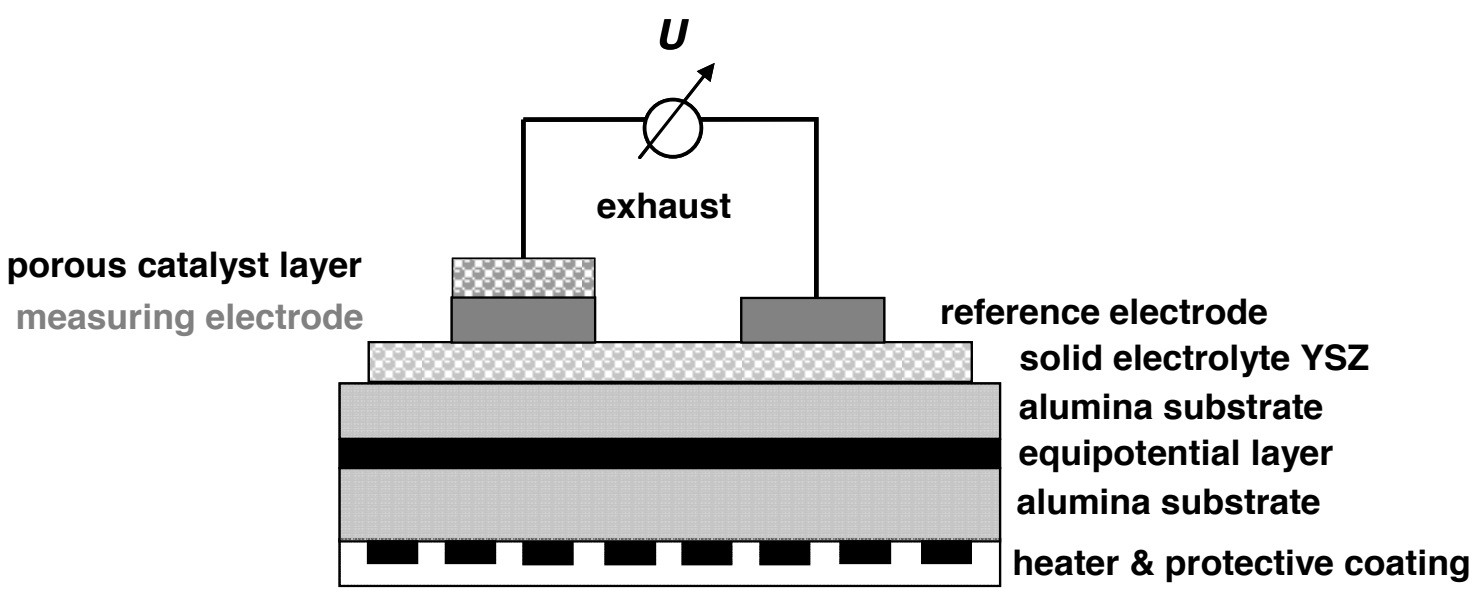

Fig. 1 Sensor setup in ceramic multi-layer technology

\section{Results and Discussion}

The $U\left(c_{N H 3}\right)$ sensor characteristic curve (Fig. 2) shows a semi-logarithmic behaviour with a slope of $88 \mathrm{mV}$ per decade $\mathrm{NH}_{3}$. The sensor shows its highest sensitivity at low $\mathrm{NH}_{3}$ concentrations and the detection limit of the sensor is against $1 \mathrm{ppm} \mathrm{NH}_{3}$. The calculated slope is in good accordance with the mixed potential ammonia sensor presented in [3] (80 $\mathrm{mV} /$ decade $\left.\mathrm{NH}_{3}\right)$.

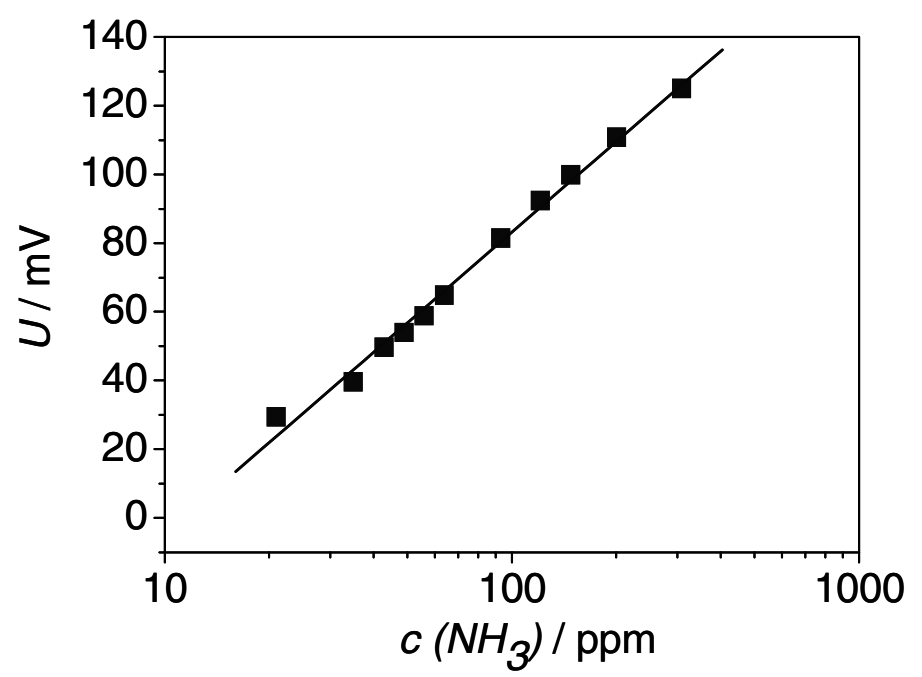

Fig. 2 Characteristic sensor response curve in dependence of the ammonia concentration

The influence of $\mathrm{NO}_{x}$ on the $\mathrm{NH}_{3}$ signal, presented in Fig. 3, is the most interesting point concerning the sensor application in SCR systems. In Fig. $3, \Delta U$ is plotted semi-logarithmically against the $\mathrm{NH}_{3}$ concentration for a background gas containing 0 or $160 \mathrm{ppm} \mathrm{NO}\left(\mathrm{NO} / \mathrm{NO}_{2}=1\right)$. The signal behaves almost independent from the background gas composition. Comparing both curves illustrates that the $\mathrm{NO}_{x}$ influence on the $\mathrm{NH}_{3}$ sensitivity is marginal for $\mathrm{NH}_{3}$ concentrations above $20 \mathrm{ppm}$. For low $\mathrm{NH}_{3}$ concentrations, a small influence in the range of $5 \mathrm{mV}$ is visible in the inset graph of Fig. 3. Depending on the working point, a slightly higher measured ammonia concentration value in the range of $4 \mathrm{ppm} \mathrm{NH}_{3}$ is 
the consequence. The $\mathrm{NO}_{x}$ cross interference on the $\mathrm{NH}_{3}$ signal decreases with decreasing $\mathrm{NO}_{x}$ and especially with decreasing $\mathrm{NO}_{2}$ concentration [4].

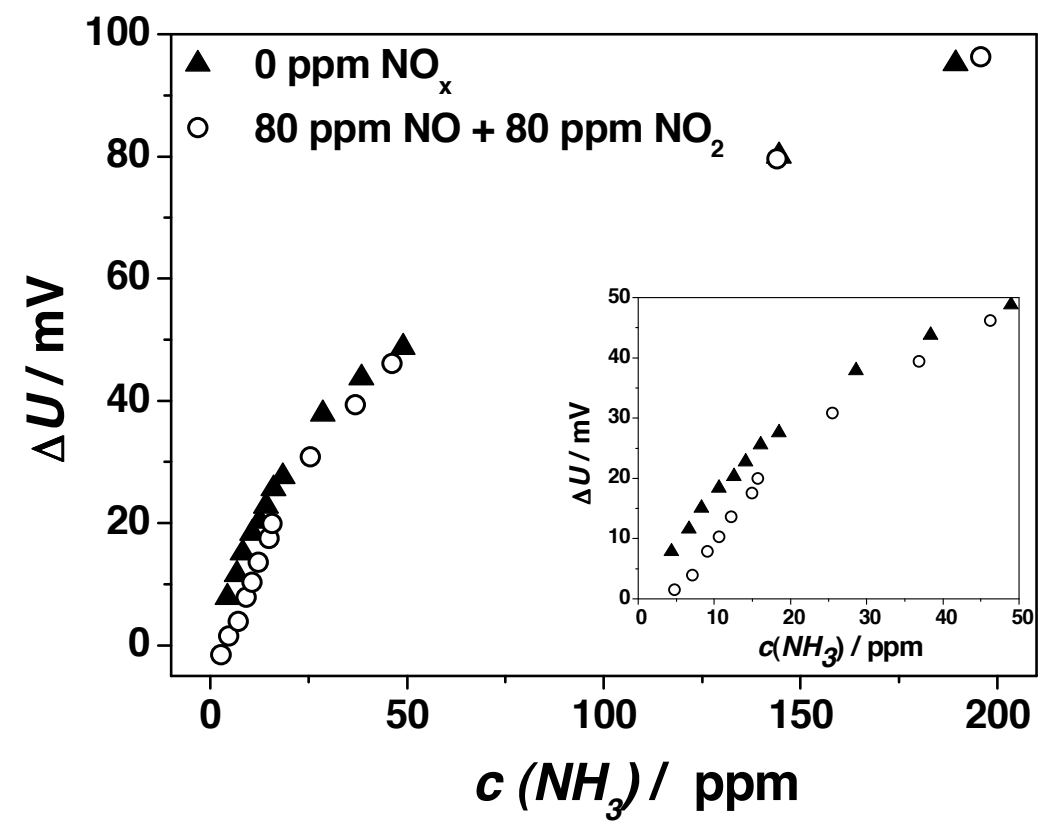

Fig. $3 \mathrm{NO}_{x}$ influence on the $\mathrm{NH}_{3}$ sensor

Another crucial point is the dependency of the sensor signal on $\lambda$ fluctuations. $\lambda$ was varied in lean atmosphere from $1.9\left(10 \% \mathrm{O}_{2}, 6.6 \% \mathrm{CO}_{2}, 7 \% \mathrm{H}_{2} \mathrm{O}, \mathrm{N}_{2}\right)$ to $1.05\left(0.93 \% \mathrm{O}_{2}, 12.1 \% \mathrm{CO}_{2}, 13 \% \mathrm{H}_{2} \mathrm{O}, \mathrm{N}_{2}\right)$ by adjusting the concentrations of $\mathrm{O}_{2}, \mathrm{CO}_{2}$ and $\mathrm{H}_{2} \mathrm{O}$. The dependency of the sensor signal on $\lambda$ is demonstrated exemplary in Fig. 4 for $\lambda=1.86$ and 1.047 .

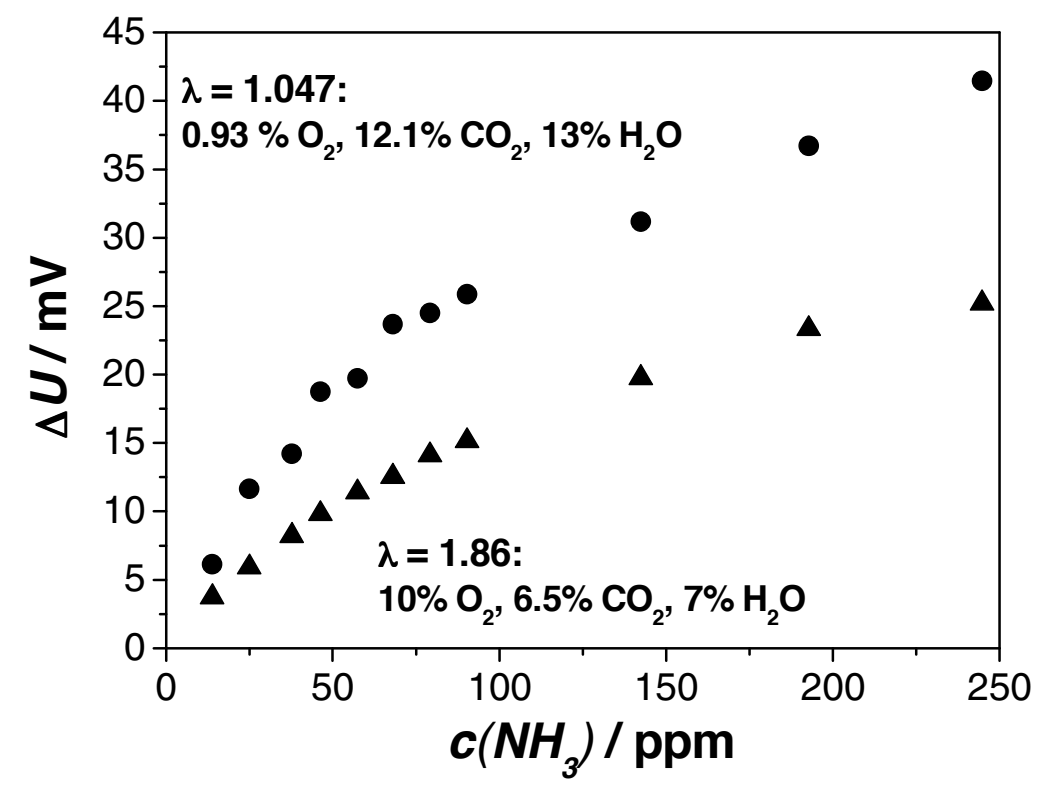

Fig. $4 \lambda$-dependency of the $\mathrm{NH}_{3}$ sensor signal

The $\mathrm{NH}_{3}$ sensor signal increases with a decreasing $\lambda\left(\mathrm{O}_{2}\right.$-changes from $10 \%$ to $\left.0.93 \%\right)$ around $10 \mathrm{mV}$. To specify if the cross interference is due to $\mathrm{O}_{2}, \mathrm{CO}_{2}$ or $\mathrm{H}_{2} \mathrm{O}$ changes, tests with only one changing gas component proofed the expectation that the $\mathrm{NH}_{3}$ sensor signal depends on the oxygen concentration. 
More specified measurements showed that the $\mathrm{NH}_{3}$ signal is nearly constant until reaching an $\mathrm{O}_{2}$ concentration of around 4\% [4]. A lower $\mathrm{O}_{2}$ concentration or smaller $\lambda$ leads to an increasing $\mathrm{NH}_{3}$ signal. It is noteworthy to mention that the $\mathrm{O}_{2}$ or $\lambda$ cross interferences can be neglected in lean atmospheres with $c\left(\mathrm{O}_{2}\right)>4 \%$.

An initital real exhaust gas measurement at steady state engine test bench operation is illustrated in Fig.

5. The measured ammonia sensor signal and the ammonia concentration determined by Laser diode spectroscopy (LDS) are plotted over the measuring time. The trend of the curves agree very well. The characterized $\mathrm{NH}_{3}$ sensor provides a stable ammonia signal and the response curve follows the measured $\mathrm{NH}_{3}$ concentration instantenously.

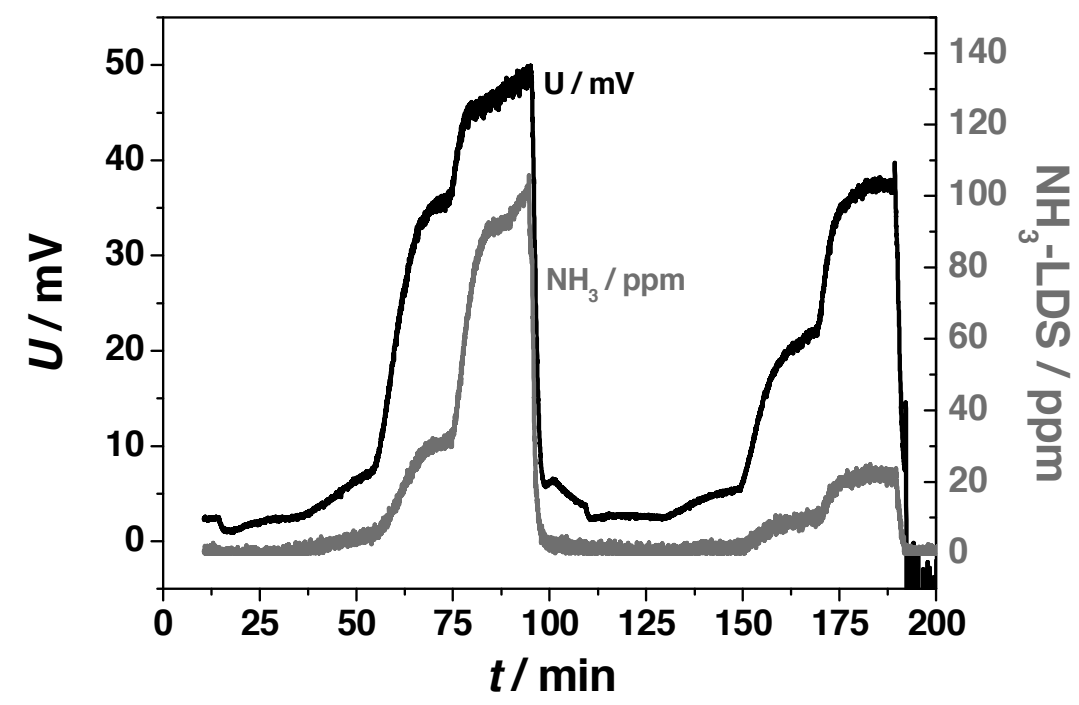

Fig. 5. Engine test bench result for steady state operation black: ammonia sensor signal in $\mathrm{mV}$, grey: $\mathrm{LDS}-\mathrm{NH}_{3}$ concentration in ppm

\section{Conclusion}

The presented ammonia exhaust gas sensor shows promising results for the detection of $\mathrm{NH}_{3}$ in harsh environments. The slight $\mathrm{NO}_{\mathrm{x}}$ interference on the ammonia signal is combined with a marginal $\lambda$ dependency at $\lambda>1.1$. Engine test bench measurements showed promising results. The novel sensor setup provides the possibility to optimize the electrode configuration independently from the catalyst material. As catalyst material also electrically insulating materials can be characterized, because they only have to provide catalytic activity and long-term stability. Optimizing both electrode layers separately offers a method to develop designing selective, sensitive and long-term stable sensors.

\section{References}

1. Aneja, R. et al., $10^{\text {th }}$ DEER Conference, Coronado, CA (2004).

2. Wang, D.Y. et al., $12^{\text {th }}$ IMCS, Columbus, Ohio (2008).

3. Wang et al., SAE2008-01-0919.

4. Schönauer et al., Sensoren im Automobil 2009, expert Verlag, in press. 